\title{
A Crop Loss-Related Forecasting Model for Sclerotinia Stem Rot in Winter Oilseed Rape
}

\author{
S. Koch, S. Dunker, B. Kleinhenz, M. Röhrig, and A. von Tiedemann
}

First, second, and fifth authors: Department of Crop Science, Plant Pathology and Plant Protection section, Georg-August University Göttingen, Grisebachstraße 6, 37077 Göttingen, Germany; third author: Center Institution for Decision Support Systems in Crop Protection (ZEPP), Rüdesheimer Straße 60-68, 55545 Bad Kreuznach, Germany; and fourth author: Information System for Integrated Plant Production (ISIP), Rüdesheimer Straße 60-68, 55545 Bad Kreuznach, Germany.

Accepted for publication 16 April 2007.

\begin{abstract}
Koch, S., Dunker, S., Kleinhenz, B., Röhrig, M., and von Tiedemann, A. 2007. A crop loss-related forecasting model for Sclerotinia stem rot in winter oilseed rape. Phytopathology 97:1186-1194.

Sclerotinia stem rot (SSR) is an increasing threat to winter oilseed rape (OSR) in Germany and other European countries due to the growing area of OSR cultivation. A forecasting model was developed to provide decision support for the fungicide spray against SSR at flowering. Four weather variables-air temperature, relative humidity, rainfall, and sunshine duration-were used to calculate the microclimate in the plant canopy. From data reinvestigated in a climate chamber study, 7 to $11^{\circ} \mathrm{C}$ and 80 to $86 \%$ relative humidity $(\mathrm{RH})$ were established as minimum conditions for stem infection with ascospores and expressed as an index to discriminate infection hours (Inh). Disease incidence (DI) significantly correlated with Inh occurring post-growth stage (GS) 58 (late bud stage) $\left(r^{2}=0.42, P \leq 0.001\right)$. Using the sum of Inh from continuous infection periods exceeding $23 \mathrm{~h}$ significantly improved correlation with DI $\left(r^{2}=\right.$ $0.82 ; P \leq 0.001)$. A parallel GS model calculates the developmental stages of OSR based on temperature in the canopy and starts the model calculation at GS 58. The novel forecasting system, SkleroPro, consists of a two-tiered approach, the first providing a regional assessment of the disease risk, which is assumed when 23 Inh have accumulated after the crop has passed GS 58. The second tier provides a field-site-specific,

yield, and price of rapeseed, the number of Inh corresponding to DI at the economic damage threshold $\left(\mathrm{Inh}_{\mathrm{i}}\right)$ is calculated. A decision to spray is proposed when $\mathrm{Inh} \geq \mathrm{Inh}_{\mathrm{i}}$. Historical field data (1994 to 2004) were used to assess the impact of agronomic factors on SSR incidence. A 2-year crop rotation enhanced disease risk and, therefore, lowered the infection threshold in the model by a factor of 0.8 , whereas in 4-year rotations, the threshold was elevated by a factor 1.3. Number of plants per square meter, nitrogen fertilization, and soil management did not have significant effects on DI. In an evaluation of SkleroPro with 76 historical (1994 to 2004) and 32 actual field experiments conducted in 2005, the percentage of economically correct decisions was 70 and $81 \%$, respectively. Compared with the common practice of routine sprays, this corresponded to savings in fungicides of 39 and $81 \%$ and to increases in net return for the grower of 23 and $45 € /$ ha, respectively. This study demonstrates that, particularly in areas with abundant inoculum, the level of SSR in OSR can be predicted from conditions of stem infection during late bud or flowering with sufficient accuracy, and does not require simulation of apothecial development and ascospore dispersal. SkleroPro is the first crop-loss-related forecasting model for a Sclerotinia disease, with the potential of being widely used in agricultural practice, accessible through the Internet. Its concept, components, and implementation may be useful in developing forecasting systems for Sclerotinia diseases in other crops or climates.
\end{abstract} economy-based recommendation. Based on costs of spray, expected
Sclerotinia stem rot (SSR), caused by Sclerotinia sclerotiorum (Lib.) de Bary, poses an increasing threat to oilseed rape (OSR), Brassica napus, in Germany, its growing importance being a consequence of the increased intensity in cultivation of this oil crop in the last two decades $(32,34)$. In the United Kingdom, yield losses of up to $50 \%$ due to this disease have been reported (26) whereas, in Germany, up to $70 \%$ incidence of stem rot (unpublished data) has been recorded in areas with short crop rotation such as the coastal region of the northeast (Mecklenburg-Western Pomerania), which may result in yield losses of 20 to $30 \%$ (9). At present, control of SSR in winter OSR relies predominantly on one fungicide spray at the time of flowering aimed at controlling the infection of stems by ascospores. Because resistant cultivars are not available, prophylactic fungicide sprays at full bloom have become a widely applied control practice. However, earlier analyses of a large number of field experiments conducted from 1981 to 1991 and from 1992 to 2004 have shown only 27 and 33\% of fungicide sprays at bloom to be cost-effective $(8,9,33)$.

Corresponding author: A. von Tiedemann; E-mail address: atiedem@gwdg.de

doi:10.1094/PHYTO-97-9-1186

(C) 2007 The American Phytopathological Society
This unsatisfactory situation has given rise to the development of various approaches of decision support systems for this disease. Disease prediction models require comprehensive knowledge of the environmental and agronomical determinants of the pathogen life cycle and the final disease level $(6,27)$. Optimal temperatures for Sclerotinia infection in lettuce are 16 to $27^{\circ} \mathrm{C}$ (37), but infections on stems of OSR also have been observed at $8^{\circ} \mathrm{C}$, if relative humidity $(\mathrm{RH})$ was $>92 \%$, whereas the optimal $\mathrm{RH}$ ranged from 84 to $100 \%$ (19). A scanning electron microscope (SEM) study demonstrated the requirement for optimal conditions to last for 20 to $30 \mathrm{~h}$ to enable infection of leaves by ascospores deposited on petals (17). Previous attempts to produce simple prediction systems have been based on field-site-specific factors and the weather conditions during flowering $(2,3)$. Such approaches have been extended by recording the emergence of apothecia in the field by means of sclerotial depots $(18,24)$. In addition, the timing and intensity of ascospore release were recorded with spore traps placed directly above sclerotial depots (3). Thus, an attempt was made to adequately describe the sequence of events linking apothecial growth, ascospore dispersal, and petal infection (5). By adding field-site-specific risk factors, Ahlers et al. (4) developed a system for predicting disease incidence (DI) on which to base a fungicide recommendation. The predictive accuracy of this sys- 
tem was $\approx 60 \%$, with a prevailing overestimation of the disease. In a further step, a threshold value of $10 \%$ DI was proposed for costeffective fungicide use at growth stage (GS) 61 to 67 (flowering stages, according to Lancashire et al. [20]) (4). A simple tool for supporting a decision of fungicide spray in spring-sown canola was developed in Sweden utilizing a checklist for risk points based on various field-specific parameters (31). Risk points were calculated from six risk factors: precipitation, the short-term weather forecast, previous disease levels, frequency of OSR cultivation, crop density, and development of apothecia.

Another approach has been the agrometeorological model SKLERO in Germany $(11,12)$, which, however, was constricted to estimate the likelihood of an infection rather than to predict the level of disease or crop loss. Similarly, previous approaches to forecast SSR lacked an economic evaluation of the cost-effectiveness of a spray. These early models also had a low degree of computerization and required a relatively time-consuming collection and input of field-specific data (e.g., on the emergence of apothecia or ejection of ascospores) $(4,12,24,31)$, thereby additionally enhancing the likelihood of inaccuracy. An approach to quantitative forecasts of SSR based on a petal infestation test has been developed in Canada for spring-sown canola (15). Petals were collected from the field during the time of flowering and analyzed for the presence of S. sclerotiorum. When data on petal infection were combined with various canopy variables (leaf area index, light penetration, and plant height) in multiple regression analyses, 55 to $98 \%$ of the variability in DI at harvest time was explainable (30). This decision support system is able to integrate the ascospore inoculum originating from apothecia from both inside and outside the field and landing on the crop; however, it requires several assessments of petal infestation during flowering stages. In the United Kingdom, attempts have been undertaken recently to predict the carpogenic germination of sclerotia based on air temperature and the soil water potential and to evaluate whether this can be used in a disease forecasting system for Sclerotinia leaf drop in lettuce $(6,38)$. However, apothecial development was found to be determined by a complex of factors which requires a closer analysis before it can be utilized in a reliable forecasting system. None of the previous efforts for implementing decision support tools for control of SSR have achieved a wider practical application. The main reasons for that are lacking reliability, requirement of too many input data to be manually provided by the user, and a lack of infrastructure to deliver such tools to the agricultural practice.

The present work aimed at developing a crop-loss-related forecasting model for SSR in areas with typical OSR cultivation and, hence, abundant inoculum, enabling a field-site-specific recommendation on fungicide sprays at flowering. More specifically, the novel forecasting model SkleroPro was intended to provide an accurate and easy-to-handle, fully computerized decision support system based on weather and field-site-specific data, and made accessible to growers and advisors via the Internet. This work describes the model concept and its components, and provides data on its validation under field conditions in diverse geographical situations.

\section{MATERIALS AND METHODS}

Historical field data. The data set comprised historical data from 650 field trials conducted by the Federal State extension services over a period of 10 years (1994 to 2004). Analysis of variance was used to determine the impact of different fieldspecific factors on DI (Table 1). Factors having a significant impact on disease severity were candidate predictors for the fieldsite-specific disease level. Effects of year, number of plants per square meter, $\mathrm{N}$ fertilization, and frequency of OSR in the crop rotation were analyzed from this data set. In addition, if corresponding weather data were available, the historical field data were used for calculating correlations of DI with weather variables.

Field trials for model testing. Field-specific data such as date of mid-bud stage (GS 55, all inflorescences developed but still closed) (20), DI, and yield were collected from field experiments in collaboration with the Federal State extension services during three growing seasons (2002 to 2004). The experiments were located in 10 Federal States (Mecklenburg Western-Pomerania, Schleswig-Holstein, Lower Saxony, Brandenburg, Saxony, Thuringia, Northrhine-Westfalia, Rhineland-Palatinate, Bavaria, and Saxony-Anhalt) (Fig. 1) where OSR is commonly grown and comprised untreated plots and plots treated at flowering stages (GS 61 to $69 ; 10$ to $100 \%$ inflorescences open) (20) with fungicide arranged in a randomized block design with four replicates. The experiments were conducted for three purposes: first, to relate DI to weather variables; second, to test the crop growth model for accuracy; and third, to evaluate the economic efficiency of SkleroPro.

In 2005, SkleroPro was evaluated concomitantly in 32 field sites in different parts of Germany. Each field experiment comprised a fungicide-untreated control, one treatment following the model recommendation, and a grower's variant with routine fungicide application at full bloom (GS 65; 50\% of flowers open). Plots were arranged in a randomized block design with four replications in each experiment. All fungicide treatments were performed with Cantus at 0.5 liter/ha (a.i. Boscalid, registered trademark of BASF).

Weather data. Weather data were obtained online from the German Meteorological Service (DWD) in Offenbach through the Centre Institution for Decision Support Systems in Crop Protection (ZEPP). Further weather data were obtained directly from the Federal State extension service stations online. The entire data set included hourly readings of temperature $\left({ }^{\circ} \mathrm{C}\right)$ and $\mathrm{RH}(\%)$, both recorded $2 \mathrm{~m}$ above ground, and precipitation $(\mathrm{mm})$ for the period from 1995 to 2005 . The same set of weather data was

TABLE 1. Effect of agronomic factors on the incidence of Sclerotinia stem rot on oilseed rape (OSR) calculated from historical data from field trials conducted in different Federal States in Germany, 1994 to 2004

\begin{tabular}{|c|c|c|c|}
\hline Factor, classification & $N^{\mathrm{a}}$ & $\mathrm{DI}(\%)^{\mathrm{b}}$ & $F$ value $^{\mathrm{c}}$ \\
\hline Frequency of OSR in crop rotation & $\ldots$ & & $3.3^{*}$ \\
\hline$>3$-year rotation & 81 & 11.0 & $\ldots$ \\
\hline 3-year rotation & 13 & 15.0 & $\ldots$ \\
\hline 2-year rotation & 5 & 19.0 & $\ldots$ \\
\hline Number of plants & $\ldots$ & $\ldots$ & $2.8 \mathrm{~ns}$ \\
\hline Low $\left(<30\right.$ plants $\left./ \mathrm{m}^{2}\right)$ & 24 & 6.5 & $\ldots$ \\
\hline Medium (30-50 plants $\left./ \mathrm{m}^{2}\right)$ & 37 & 9.0 & $\ldots$ \\
\hline High $\left(>60\right.$ plants $\left./ \mathrm{m}^{2}\right)$ & 22 & 14.0 & $\ldots$ \\
\hline Nitrogen fertilization level & $\ldots$ & $\ldots$ & $0.7 \mathrm{~ns}$ \\
\hline Low $(<175 \mathrm{~kg} / \mathrm{ha})$ & 15 & 14.3 & $\ldots$ \\
\hline Moderate $(175-220 \mathrm{~kg} / \mathrm{ha})$ & 19 & 24.4 & $\ldots$ \\
\hline $\operatorname{High}(>220 \mathrm{~kg} / \mathrm{ha})$ & 11 & 21.5 & $\ldots$ \\
\hline Soil tillage & $\ldots$ & $\ldots$ & $0.3 \mathrm{~ns}$ \\
\hline Ploughed & 67 & 10.1 & $\ldots$ \\
\hline Nonploughed & 32 & 12.0 & $\ldots$ \\
\hline Year of observation & $\ldots$ & $\ldots$ & $70.4 * * *$ \\
\hline 1994 & 56 & 1.8 & $\ldots$ \\
\hline 1995 & 60 & 5.2 & $\ldots$ \\
\hline 1996 & 51 & 5.3 & $\ldots$ \\
\hline 1997 & 56 & 16.0 & $\ldots$ \\
\hline 1998 & 49 & 6.0 & $\ldots$ \\
\hline 1999 & 67 & 5.0 & $\ldots$ \\
\hline 2000 & 63 & 9.7 & $\ldots$ \\
\hline 2001 & 68 & 12.4 & $\ldots$ \\
\hline 2002 & 57 & 26.6 & $\ldots$ \\
\hline 2003 & 23 & 2.8 & $\ldots$ \\
\hline 2004 & 31 & 24.3 & $\ldots$ \\
\hline
\end{tabular}

a Number of field trials.

b Disease incidence.

${ }^{c}$ Symbols $*$ and $* * *$ indicate significance at $P \leq 0.05$ and 0.001 , respectively; ns $=$ not significant. 
obtained from 46 additional meteorological stations in Germany. In general, $94 \%$ of the field trials were located at a distance $<20$ $\mathrm{km}$ away from the closest weather station.

Analysis of cost effectiveness of fungicide sprays. The economic validation of SkleroPro was performed by retrospective calculations using historical data from 76 field trials run by the Federal State extension services and the corresponding weather data from the period 1994 to 2004. In addition, the model was tested in 32 field trials in 2005. The model performance was evaluated with regard to the percentage of economically correct decisions to spray or not to spray during flowering, and regarding the precision of timing of the application. Spray costs included fungicide prices plus value-added tax (VAT), variable application costs, and losses due to tractor damage to the flowering crop. The calculation of the variable application costs was based on data published by the Association for Technology and Structures in Agriculture (KTBL) and consisted of machine costs (standard tractor with four-wheel drive, 75 to $92 \mathrm{~kW}, 1,000$-liter mounted sprayer, and 15-m application width) and labor costs (labor time requirement based on 200 liter/ha application volume, field size 2 ha, average foreman wage costs). Yield losses due to tractor damage at the time of full bloom were estimated to $2.6 \%$. OSR seed prices were averaged for the respective growing season.

Environmental determinants for OSR stem infection with S. sclerotiorum. Experiments under controlled conditions were carried out in order to revisit the optimum requirements for ascospore infection of Sclerotinia spp. on stems of OSR given in the literature. Conditions of infection with ascospores reported previously vary from 8 to $27^{\circ} \mathrm{C}(4,37)$, with an optimum in the range from 16 to $20^{\circ} \mathrm{C}$ (1). For the approach taken with SkleroPro, it was particularly important to precisely determine the critical

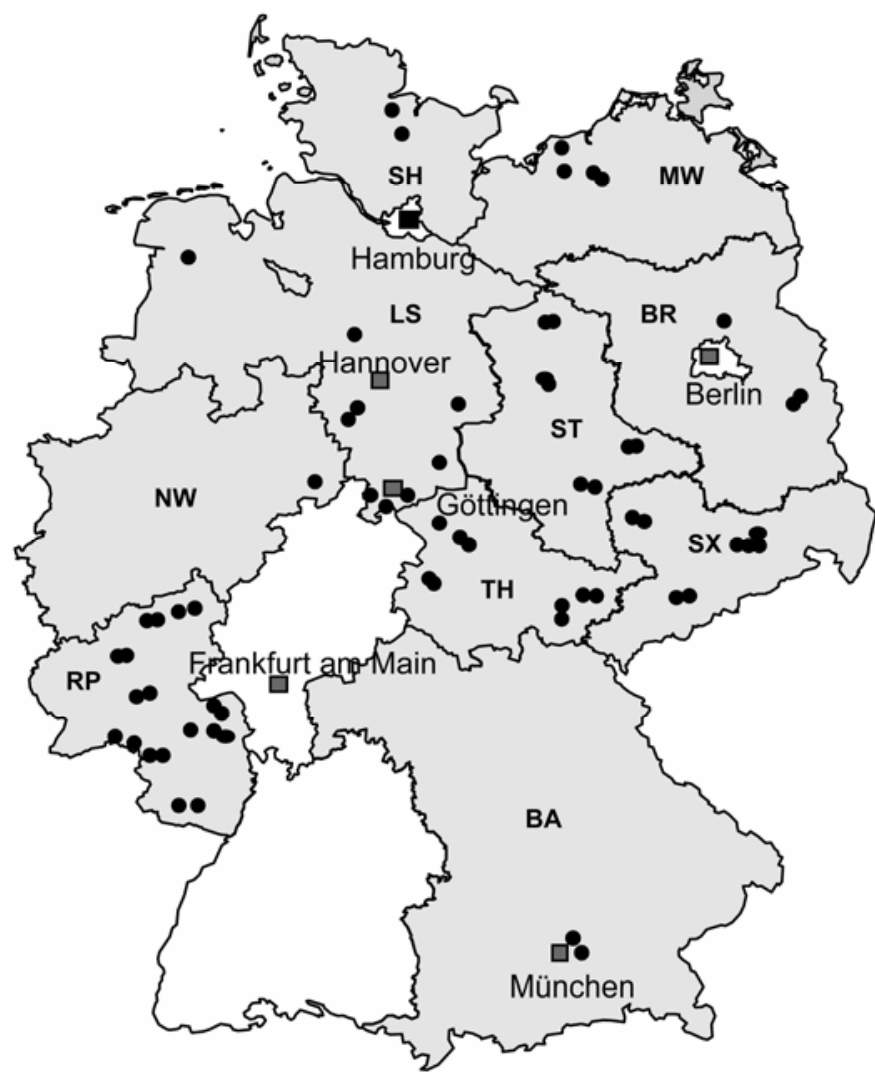

Fig. 1. Locations of field trials (dots) for developing, testing, and evaluating SkleroPro in ten Federal States (dark gray) of Germany from 2002 to 2005. MW = Mecklenburg-Western Pomerania, SH = Schleswig-Holstein, LS = Lower Saxony, BR = Brandenburg, $\mathrm{TH}=$ Thuringia, $\mathrm{NW}=$ NorthrhineWestfalia, RP = Rhineland-Palatinate, $\mathrm{BA}=$ Bavaria, $\mathrm{ST}=$ Saxony-Anhalt , and $\mathrm{SX}=$ Saxony. threshold temperatures where stem infections may or may not occur. Thresholds for RH required for infection were extrapolated from the literature $(1,19)$.

Seed of cv. Heros were germinated at room temperature for 4 days in boxes with a soil/sand mixture. The seedlings were transplanted in 11.5-by-11.5-cm pots with soil consisting of compost, sand, and standard soil $(2: 1: 1, \mathrm{vol} / \mathrm{vol})$. Plants were grown under normal conditions ( $12 \mathrm{~h}$ of light per day, $18^{\circ} \mathrm{C}$ ). At GS 65 (full bloom), stem segments (length $8 \mathrm{~cm}$ ) were excised from six plants at $30-\mathrm{cm}$ plant height, including an axil with a side shoot. Sixteen boxes ( 24 by 34 by $14 \mathrm{~cm}$ ) with a horizontal wire grid and an airtight lid were used for incubation. The grid served to hold stem segments $\approx 1 \mathrm{~cm}$ above a water surface on the bottom of the box ( 1 liter of water per box). There were six stems per box held by the grid. A petal was placed at each of the axils of three stems and a 10- $\mu$ l drop of ascospore suspension $\left(5 \times 10^{4} \mathrm{ml}^{-1}\right.$ spores) was placed on the petal. Ascospores were produced by inducing carpogenic germination of sclerotia incubated in sand/ soil mixture for 4 weeks at 15 and $10^{\circ} \mathrm{C}$ (day and night) in the dark, followed by $\approx 5$ to 6 weeks at $18^{\circ} \mathrm{C}$ under near-UV light (12 h per day) until mature apothecia formed. Sclerotinia isolates were obtained from a mixture of sclerotia collected from diseased OSR plants at various locations in Germany. Ascospores were captured from mature apothecia in Eppendorf tubes placed above. Ascospores were stored in a $50 \%$ aqueous glycerine solution at $-20^{\circ} \mathrm{C}$. On the remaining three stems, the ascospore suspension was placed directly on the stem axil without petal. The stems were incubated at temperatures from 6 to $28^{\circ} \mathrm{C}$ in $2^{\circ} \mathrm{C}$ steps at saturated humidity in a climate chamber in the dark. Disease severity on stems was recorded daily for 14 days. There were six stems used for each temperature and the experiment was conducted two times.

Statistical analyses. The readings of DIs in the different field trials of the historical data set were not normally distributed. Therefore, a nonparametric analysis of variance was carried out to analyze the impact of field-specific factors on DI. Data were ranked by ordering them from lowest to highest and assigning them to ordinal numerals from 1 to $n$ (sample size). The nonparametric analysis was performed with the "R" statistical package (version 1.7.1) (13). Significant differences between mean values were determined by $F$ test at significance levels of $P \leq 0.1$ ('), $P \leq 0.05$ (*) $^{*} P \leq 0.01$ (**), and $P \leq 0.001$ (***). The simulation model software ModelMaker was used for the development, modification, optimization, and evaluation of the prediction model (35). Regression analysis was used to test the relationship between number of infection hours and DI within the statistical program STATGRAPHICS (version 5.0).

\section{RESULTS}

Identification of field-site-specific determinants of DI. The level of DI varied strongly with the year of observation (Table 1). Except for 2003, which was an extremely hot and dry year in Germany, there was a trend of increasing SSR incidence in the last 10 years. Highest DI was recorded in 1997, 2002, and 2004, which were characterized by an extremely wet spring and early summer.

The majority of OSR in Germany is grown on loamy or sandy soils, because heavier soils and clay soils are less suitable due to the deep root development. The data available on the soil type were limited and insufficiently classified; therefore, the soil type was excluded from the model as determinant.

The strongest field-site-specific factor was the frequency of OSR cultivation in the crop rotation when comparing 2-, 3-, and $>3$-year cycles, and it revealed an enhancement of DI with higher frequencies of the crop. In contrast, no significant relationship with DI was found for number of plants and soil management (ploughed versus nonploughed). The level of nitrogen fertilization 
was split into three categories: low ( $<175 \mathrm{~kg} / \mathrm{ha})$, medium (175 to $220 \mathrm{~kg} / \mathrm{ha})$, and high (>220 kg/ha), but also had no significant effect on DI (Table 1).

Environmental conditions for infection. SSR developed on inoculated stems most rapidly at 16 to $22^{\circ} \mathrm{C}$ where mycelial growth was observed within 4 days after inoculation and first disease symptoms became visible 7 to 9 days later. After 12 days, the whole stem sample was covered with mycelium. At 7 to $12^{\circ} \mathrm{C}$ and $>22^{\circ} \mathrm{C}$, the disease developed more slowly, due to mycelial growth being strongly delayed by $\approx 10$ days. At $<7^{\circ} \mathrm{C}$ and $>26^{\circ} \mathrm{C}$, no mycelium and infection were detected, regardless of whether fallen petals were present or not. However, at suitable temperatures, petals played an essential role in the ascospore infection, with an average of $23 \%$ DI on the stem axils without a petal versus $100 \%$ infection in the presence of petals (data not shown).

Structure, components, and calculations of SkleroPro. A functional scheme depicting input and output variables and determinants of SkleroPro is represented in Figure 2. SkleroPro uses weather data from the closest weather station on $\mathrm{RH}$ and temperature (measured hourly at $2 \mathrm{~m}$ above ground), precipitation (hourly reading), and sunshine duration (hours per day) for its initial computation step, in which these weather data are transformed into temperature (T-Cpy) and relative humidity (RH-Cpy) in the plant canopy (CLIMA Cpy) of an OSR stand. The computation starts at the day when the late bud stage (GS 58) is passed. The date of mid-bud stage (GS 55) and the kind of crop rotation
(CropR) are to be provided by the user to start the model. Crop development is modeled separately by a parallel calculation based on T-Cpy (ONTO; see below). From field observations, the period of risk for SSR infection is assumed to start at GS 58 (late-bud stage) which, therefore, is the starting point of the model. For practical reasons, forecasting calculations end at GS 68 (late bloom) because no later sprays in the field are feasible, although later stem infections may occur. However, in a separate study, late infections have been shown to have relatively little effect on yield (9).

The forecasting is a two-tiered procedure, starting with a regional disease risk assessment which is followed by a field-sitespecific forecast. Starting at late-bud stage (GS 58), the model calculates the number of infection hours (Inh) (see below). A regional risk of disease is assumed if the critical threshold of 23 Inh is reached after the crop has passed GS 58. In such case, the sum of Inh from continuous infection periods exceeding $23 \mathrm{~h}$ is rocorded (InhSum). Technically, the crop rotation effect is included in the model as a modulating factor of the threshold of Inh for stem infection. From the analysis of variance with historical data (Table 1), an average DI of $11 \%$ was recorded for $>3$-year crop rotations, $15 \%$ for 3 -year crop rotations, and $19 \%$ in rotations of $<3$ years. Because the 3 -year crop rotation is commonplace in OSR production in Germany, it is given the modulation factor 1. Accordingly, the increased disease risk in a 2-year crop rotation is accounted for by an Inh threshold for infection reduced

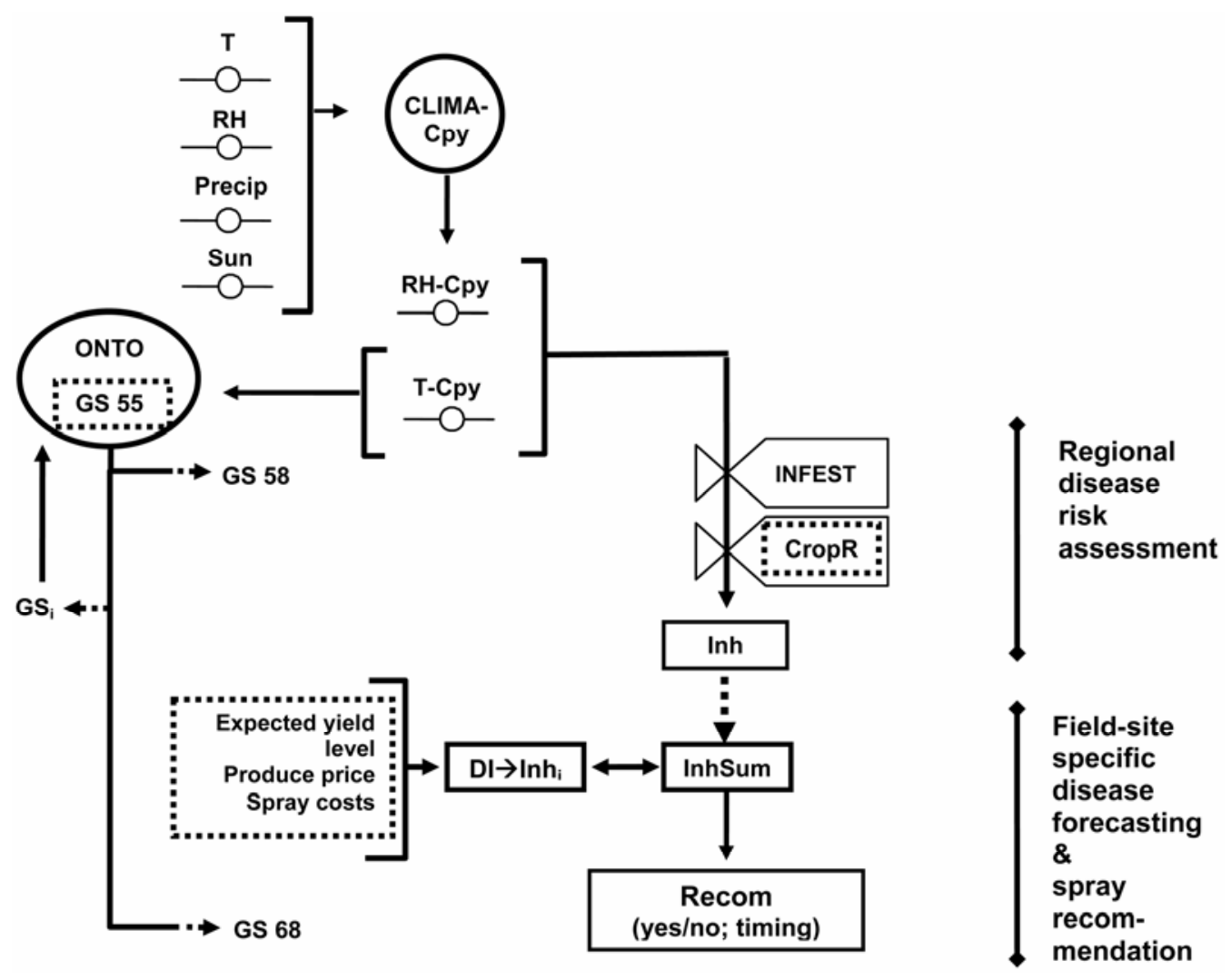



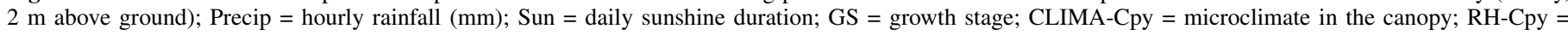

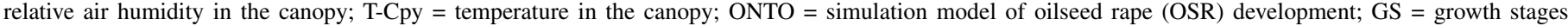

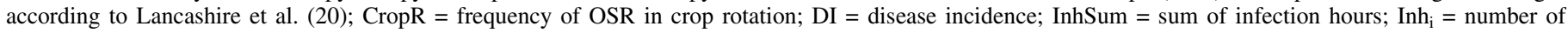

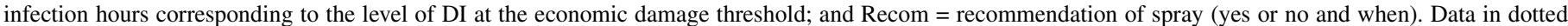





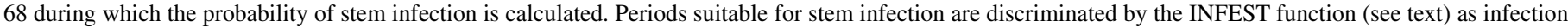

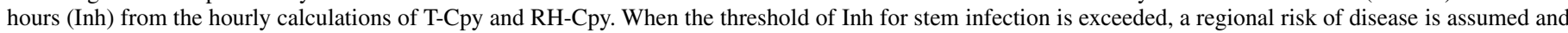

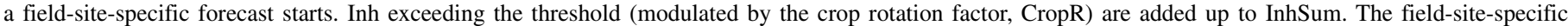

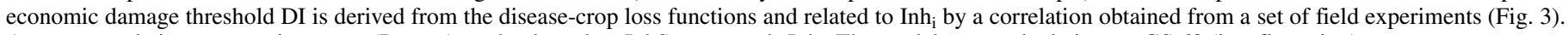
A recommendation to spray is put out (Recom) on the day when InhSum exceeds Inh $_{\mathrm{i}}$. The model stops calculations at GS 68 (late flowering). 
by factor 0.8 (equals $18.4 \mathrm{Inh}$ ) and, for a $>3$-year rotation, it is increased by the factor 1.3 (equals $29.9 \mathrm{Inh}$ ).

As a result, in the first level, SkleroPro provides a regional risk assessment specified for an individual crop rotation. When the above thresholds of Inh are reached, a regional disease risk is assumed and a field-site-specific calculation is made, including economic damage threshold starts (see below). The number of Inh corresponding to the threshold DI marking the economic damage threshold for a specific field $\left(\mathrm{Inh}_{\mathrm{i}}\right.$; see below) is calculated from correlations obtained from a large set of field trials (Fig. 3). A recommendation to spray is put out when the number of Inh recorded from a weather station exceeds the number of $\operatorname{Inh}_{\mathrm{i}}$ calculated by the model.

Simulation of crop development with the GS model ONTO. The crop development during bud and flowering stages is calculated by a growth function (ESF) and a temperature function (TES). The GS model ONTO was adopted for SkleroPro from a previous model developed by the German Meteorological Service $(11,12)$. Calculations start on the day when GS 55 (bud stage) is reached (20). The daily developmental progress is determined by the actual GS and the temperature. The daily GS factor (ESF) depends on the actual stage of the crop, because the developmental progress is assumed to be larger during earlier than during later stages. In addition, a daily temperature factor (TES) is calculated by a regression equation. TES is determined from the hourly mean temperature in the plant canopy (T-Cpy). From bud stage (GS 55) to full bloom (GS 66), TES increases exponentially with rising temperature, while a linear increase is assumed at stages later than GS 66. The daily growth rate (DGR) results from multiplication of TES with ESF and is given in GS units per day.

$$
\begin{gathered}
E S F=\left\{\begin{array}{lll}
\frac{0.6}{0.02 \cdot \mathrm{e}^{(G S-55)^{2}}} & \text { if } & 55 \leq G S<61 \\
\frac{0.15}{0.05 \cdot \mathrm{e}^{(G S-61)^{2}}} & \text { if } & 61 \leq G S<65 \\
\frac{0.15}{0.05 \cdot \mathrm{e}^{(G S-65)^{2}}} & \text { if } & 65 \leq G S<75
\end{array}\right. \\
T E S=\left\{\begin{array}{lll}
\frac{1}{1+\mathrm{e}^{0.198 \cdot(25-T)}} & \text { if } & 55 \leq G S \leq 66 \\
\frac{1}{1+\mathrm{e}^{0.03 \cdot(80-T)}} & \text { if } & 66<G S<75
\end{array}\right.
\end{gathered}
$$

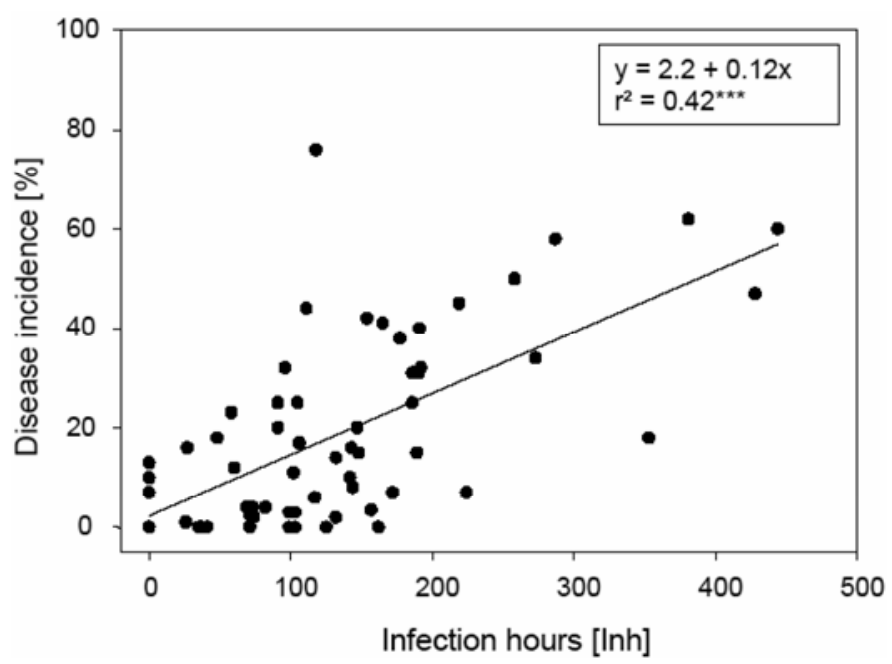

Fig. 3. Incidence of Sclerotinia stem rot in oilseed rape in relation to the number of infection hours as discriminated by the INFEST index in SkleroPro. Correlation is calculated with a data set obtained from 65 field trials conducted by the Federal States extension services in Germany from 2000 to 2004. where $T=$ hourly mean temperature in the plant canopy (T-Cpy) and DGR $=$ progress in GS units per day: DGR $=$ TES $\times$ ESF.

The accuracy of ONTO was tested in four field trials in different locations and years (Fig. 4), resulting in a satisfactory agreement between predicted and recorded GSs for the required period of OSR development. Maximum deviations from actual GSs were $<5$ days during the stages required by the model.

Determination of Inh. The chief determinant of stem infection is the number of Inh which is derived from hourly calculations of temperature and $\mathrm{RH}$ in the plant canopy (T-Cpy and RH-Cpy) (Fig. 2). According to the inoculation experiments in controlled conditions, the optimal temperature for stem rot infection was set at $18^{\circ} \mathrm{C}$ and the minimum temperature at $7^{\circ} \mathrm{C}$. Based on these temperature points and on the requirements for $\mathrm{RH}$ reported in the literature $(1,19)$ an index (INFEST) was calculated which discriminates hours suitable for infection (Fig. 5). A suitable Inh is given if INFEST is $\geq 0.005$, which depicts the threshold conditions for stem infection $\left(7\right.$ to $11^{\circ} \mathrm{C}, 80$ to $\left.86 \% \mathrm{RH}\right)$.



where $T=$ mean hourly temperature $\left({ }^{\circ} \mathrm{C}\right)$ and $R H=$ mean hourly $\mathrm{RH}(\%)$.

The minimum number of Inh for a successful infection in the field was determined by comparative regression analyses with a data set from 30 field trials conducted from 2000 to 2004. Following the SEM studies by Jameaux et al. (17), a successful infection was assumed when suitable conditions lasted for 20 to $30 \mathrm{~h}$. In a stepwise analysis in which the thresholds for stem infection in the model were varied between 20 and 30 Inh, the best correlations with DI were achieved with thresholds set at 22 or 23 Inh (Table 2). Accordingly, 23 Inh was decided in SkleroPro to be the critical threshold for a successful stem infection.

Calculation of the economic damage threshold. When a continuous infection period of 23 Inh was recorded (or 18.4 to 29.9 Inh according to the crop rotation; see above), the model started a quantitative, field-site-specific estimation of the expected level of disease and crop loss. Inh from periods exceeding the threshold for stem infection were added up to InhSum (Fig. 2). In order to calculate the economic damage threshold, the grower is asked to provide the actual rapeseed produce price, the spray costs (labor and machine costs, damage due to tractor passage through the crop, and fungicide costs) and the expected yield.

Economic calculations comprise several steps. First, spray costs are translated into yield units. These are related to the estimated crop loss derived from disease-crop loss functions developed in separate, 3-year field inoculation trials with a hybrid cultivar inoculated at full bloom $(8,9)$. Damage thresholds used by the model vary from 13 to $25 \%$ DI according to yield levels between 5 and 3 tons/ha. The DI determined as the economic damage threshold for a certain field site is related to the number of Inh by a correlation function with DI $\left(R^{2}=0.42, P \leq 0.001\right)$ gained from 65 field trials conducted from 2000 to 2004 (Fig. 3). The recommendation of the model is based on the number of Inh recorded (InhSum) versus Inh corresponding to DI at the economic threshold $\left(\mathrm{Inh}_{\mathrm{i}}\right)$. When $\mathrm{Inh}_{\mathrm{i}}$ is exceeded by InhSum, a recommendation to spray is put out on the same day.

The threshold value of $\operatorname{Inh}\left(\operatorname{Inh}_{\mathrm{i}}\right)$ representing the economic damage threshold for a specific field is calculated by

$$
\operatorname{Inh}_{i}=\frac{\frac{2.2-\frac{C \cdot 100}{P \cdot E}}{-0.35}-4.76}{0.21}
$$

where $E=$ expected yield level (dt/ha), $C=$ spray costs $(€)$, and $P=$ rapeseed produce price $(€ / \mathrm{dt})$. 
Evaluation of the prediction accuracy of SkleroPro in field trials. The prediction accuracy of SkleroPro was evaluated by retrospectively running the model with a historical data set from 76 field trials conducted from 1994 to 2004 (Table 3). The analysis revealed that $70 \%$ of the model recommendations were correct, while $24 \%$ overestimated the disease, with a final disease level being below the economic damage threshold. Underestimation occurred in $6 \%$ of the cases, resulting in sprays omitted although being cost-effective. Overall, only $53 \%$ of the routinely conducted sprays in these locations and years proved to be economically justified. Hence, SkleroPro recommendations would have saved $39 \%$ of unnecessary fungicide sprays compared with a routine application.

An additional evaluation was undertaken in field trials conducted in 32 locations in Germany in 2005, revealing an overall prediction accuracy of $81 \%$. The rate of overestimation of disease was only $19 \%$, while no case was recorded where the disease was underestimated. In the 2005 field trials, only 9\% of the sprays routinely conducted proved to be cost-effective and thus justified, because the temperature during the critical flowering stages in spring were abundantly too low. Hence, in 2005, SkleroPro would have been able to save $75 \%$ of
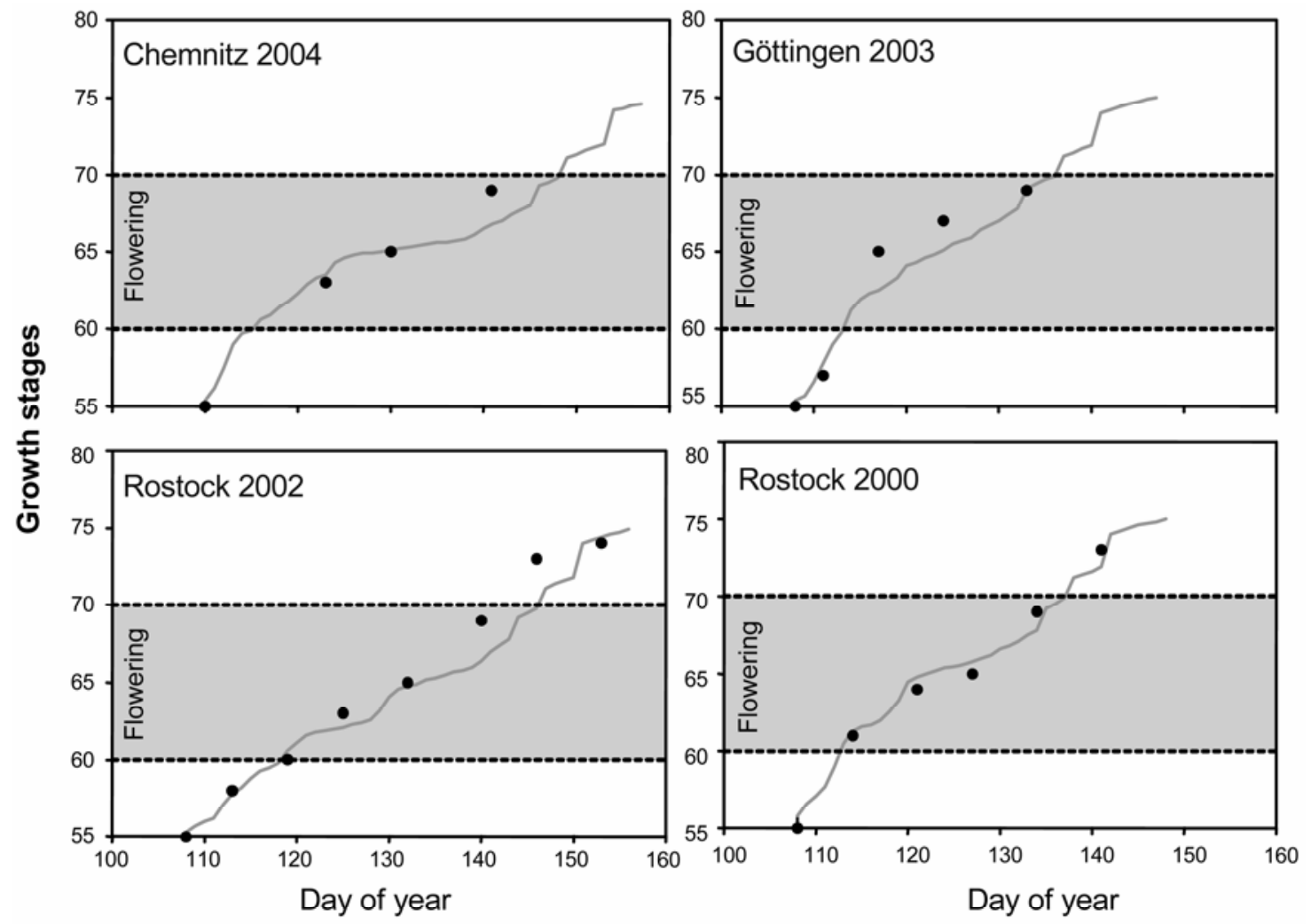

Actual growth stage $\quad$ Prediction

Fig. 4. Evaluation of the growth stage model ONTO in the field at three locations and in 4 years comparing calculated versus actual growth stages of oilseed rape (Chemnitz 2004, Göttingen 2003, and Rostock 2000 and 2002). Growth stages 60 to 70 correspond to early and late flowering stages of oilseed rape (20).
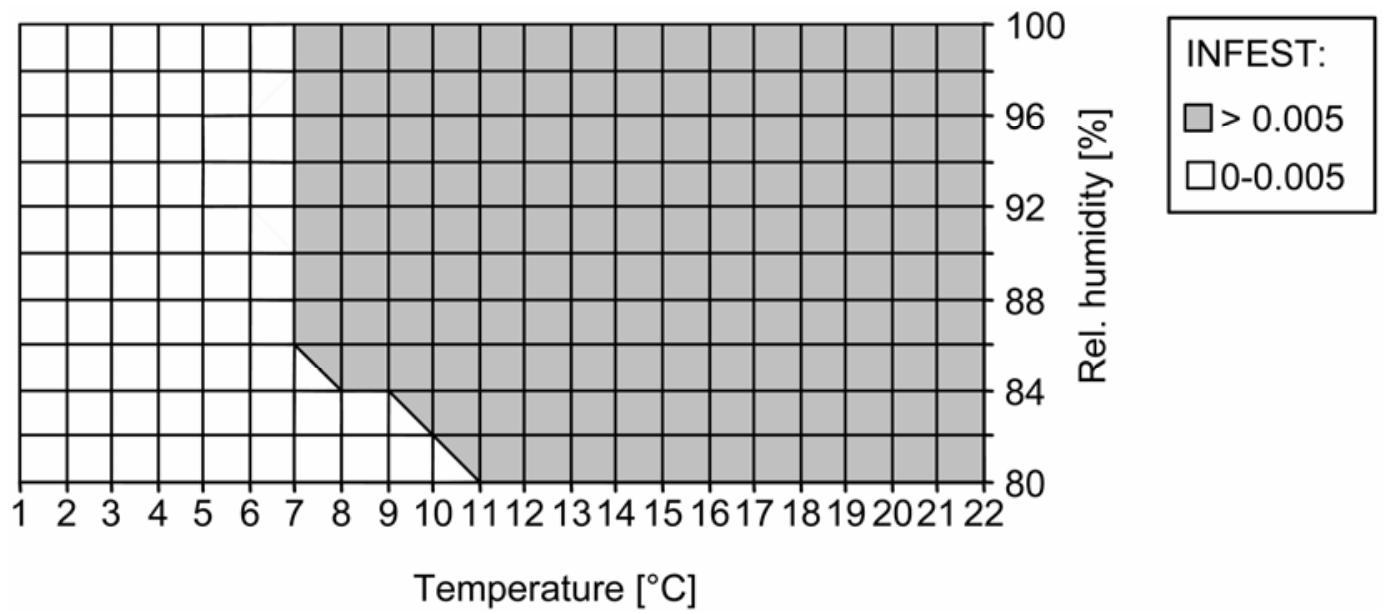

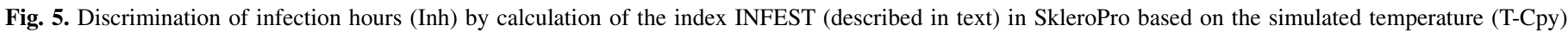
and relative humidity (RH-Cpy) in the plant cover. An infection hour requires an INFEST index of $\geq 0.005$ (shaded area). 
unnecessary fungicide sprays compared with a routine application.

\section{DISCUSSION}

This study describes the development, function, and evaluation of a crop-loss-related forecasting model for SSR in winter OSR suitable for decision support in practice. The rationale was to combine high accuracy of prediction with a minimum requirement of input data to be provided by the model user. Field-sitespecific factors such as crop rotation, number of plants, nitrogen fertilization, and soil management were analyzed for their impact on the level of DI using a comprehensive set of historical data provided from the Federal States extension services from the last 10 years. The impact of OSR cultivars was tested in separate field experiments, with the result that the presently available commercial cultivars did not significantly differ in their response to Sclerotinia spp. (8).

In the data analysis, a slightly higher DI in fields managed without ploughing was found; however, this effect was not significant. There are contrasting reports on effects of soil tillage on SSR in the literature. Although higher DI was observed after conventional tillage than in unploughed fields (21), sclerotia may survive longer when buried in greater soil depths in conventional systems (7). Continuous ploughing, however, can return well-preserved viable sclerotia back to the soil surface, where they may enhance the inoculum potential $(33,34)$. In contrast, other studies reported inoculum to be reduced faster by microorganisms when sclerotia were either buried deeper in soil after ploughing $(21,23)$ or exposed to high soil moisture under no-tillage systems (16). Because soil tillage had no significant effect on SSR in our analysis, it was not included as a factor in the forecasting model.

Previous reports have shown that infection with Sclerotinia spp. may be enhanced by a more favorable microenvironment in closer plant stands $(18,22,30)$. In contrast, the number of plants did not have a significant effect on the disease level in our analysis. It is important to note that, in a high-yield situation as in our study, the number of OSR plants does not necessarily translate into varying physical densities of the canopy, because OSR has a strong compensation potential for filling the stand space. Therefore, the varying number of plants in this study probably does not reflect varying microenvironmental conditions as addressed in most previous reports on crop density effects. This is assumed to be the reason why this factor had no significant effect on DI. The physical canopy density probably does not sufficiently vary in a highyield situation and its assessment would require technical equipment unavailable to growers (leaf area index meters and light meters); therefore, this factor was not considered in the model.

Similarly, we could not find a significant impact of nitrogen fertilization on SSR. This confirms a previous study, in which

TABLE 2. Correlations of infection hours with the disease incidence of Sclerotinia stem rot as calculated by SkleroPro when using various thresholds for the minimum required sum of continuous infection hours (InhSum) $(\text { INFEST } \geq 0.005)^{\mathrm{a}}$

\begin{tabular}{lcccc}
\hline InhSum & $\mathrm{b}(0)$ & $\mathrm{b}(1)$ & $R$ & $R^{2}$ \\
\hline 20 & -3.6 & 0.16 & 0.89 & $0.79 * * *$ \\
22 & -2.9 & 0.19 & 0.91 & $0.82 * * *$ \\
23 & -2.1 & 0.20 & 0.91 & $0.82 * * *$ \\
24 & -1.4 & 0.20 & 0.89 & $0.79 * * *$ \\
26 & 0.06 & 0.20 & 0.86 & $0.74 * * *$ \\
28 & 0.04 & 0.21 & 0.84 & $0.70 * * *$ \\
30 & 0.06 & 0.22 & 0.82 & $0.67 * * *$ \\
\hline
\end{tabular}

a INFEST $=$ index of infection hours. Analysis is based on data from 30 field trials of the Federal State extension services recorded from 2000 to 2004; $\mathrm{b}(0)=$ intercept point with $\mathrm{y}$-axis, $\mathrm{b}(1)=$ slope, $R=$ coefficient of correlation, and $R^{2}=$ coefficient of determination with significance level $* * * *=P \leq 0.001$ (Tukey test). Calculation of INFEST described in text. nitrogen, phosphorous, and potassium at normal versus elevated levels did not significantly influence the disease (19). Because nitrogen generally is provided to the crop at optimum rates and, thus, normally is not a growth-limiting factor, it was not considered as an essential factor in disease prediction.

The large increase in OSR production in Germany in the last decade (32) has been associated to a great extent with a shorter crop rotation, resulting in the increase of SSR in many areas. Accordingly, the data analysis revealed a significant effect of OSR cropping frequency on DI. Similarly, a significant effect of crop rotation with corn or winter wheat versus soybean on the production of apothecia was found (14). Because crop rotation is considered an important and independently acting field-sitespecific factor, it was included in the model as a three-tiered weighing factor for crop frequencies of 2,3 , and $>3$ years.

In the analysis of historical field data, the strongest determinant of SSR was the year of observation, illustrating the importance of environmental conditions for disease development and, thus, highlighting the great potential of a forecasting model for saving fungicide sprays in the management of SSR. Weather conditions during bud and flowering stages of OSR in spring have been shown to be the main factors in the development of SSR, whereby soil temperature, soil wetness, air temperature, and RH have been recognized as the most influential variables $(6,10,22,28,36,37)$.

In the life cycle of Sclerotinia spp., carpogenic germination of sclerotia in the soil, apothecial growth, ascospore release, and infection are considered the critical phases leading to stem rot on OSR. These processes are strongly determined by environmental conditions. Based on the description of optimal climatic conditions for carpogenic germination of sclerotia and appearance of apothecia $(6,28-30,36)$, attempts have been made to relate these processes to disease severity $(6,11,38)$. However, carpogenic germination was found to be determined by a high complexity of factors yet insufficiently understood. Thus, it appears uncertain whether and how close conditions for carpogenic germination are linked to DI. Estimation of the quantity of apothecia is even more critical because it has not been possible to establish a close quantitative relationship with disease levels $(7,9)$. In a separate study, we tested a function developed by the German Meteorological Service $(11,12)$ to predict apothecia development with calculations based on soil temperature, soil wetness, and air temperature. This model was tested from 2002 to 2004 with sclerotia buried in 28 fields, with the result of only $23 \%$ accurate predictions of the appearance time of apothecia (data not shown). Deviations in this study for the day of apothecia emergence ranged from 1 to 23 days. When including apothecia formation in a model to predict disease levels and using the historical field data, predictions were significantly less accurate than with the SkleroPro model, which is based solely on stem infection. From this comparison and the successful performance of SkleroPro, we conclude that, in areas with inoculum being widely available and soil conditions being generally conducive for apothecia development, as in most areas of winter OSR cultivation, the simulation of apothecial development and of ascospore dispersal is not re-

TABLE 3. Forecasting accuracy of SkleroPro recommendations evaluated by the percentage of economically correct decisions ${ }^{\mathrm{a}}$

\begin{tabular}{lcccc}
\hline & & \multicolumn{3}{c}{$\begin{array}{c}\text { Accuracy of model } \\
\text { recommendation (\%) }\end{array}$} \\
\cline { 3 - 5 } Data set & $n$ & Correct & Under $^{\mathrm{b}}$ & Over $^{\mathrm{c}}$ \\
\hline Historical data (1994-2004) & 76 & 70 & 6 & 24 \\
Field experiments (2005) & 32 & 81 & 0 & 19 \\
\hline
\end{tabular}

${ }^{a}$ Evaluation performed with historical field data from 1994 to 2004 and field experiments conducted in 2005 at 32 locations in Germany.

b Disease underestimated: spray would have been cost-effective, but was not recommended.

${ }^{c}$ Disease overestimated: recommended spray was not cost-effective. 
quired for achieving a satisfactory level of SSR disease prediction. Accordingly, the retrospective calculations of apothecial growth also revealed that conditions for carpogenic germination and ascospore release were given in all locations and years. Therefore, we conclude that inoculum generally is not a limiting factor in areas with a long-term history of OSR cultivation. This may be different in areas where Sclerotinia spp. occur infrequently and ascospore inoculum may be a limiting factor. Nonetheless, the field data analysis suggests that cropping frequency may still determine the amount of inoculum and, thus, has a quantitative impact on the disease level. Therefore, SkleroPro takes inoculum pressure into account by using crop rotation as a factor modulating the threshold conditions for stem infection.

A suitable method to quantify Sclerotinia inoculum is assessment of petal infestation (30), which, however, requires a significant input of labor for collecting inflorescences in the field at different time points during flowering and to assess infestation. Although petal tests may help in predicting the amount of disease, they may fail if periods with unfavorable conditions follow (30). Therefore, petal assessment may not be considered a suitable tool for a widely used low-input computerized forecasting model.

The key process modeled by SkleroPro is stem infection. In order to ensure the limiting conditions of infection, which are crucial for the model performance, and because the data reported in the literature were insufficiently consistent $(1,2,18,37)$, we reinvestigated temperature effects on infection of OSR stems with ascospores in the climate chamber. The minimum temperature for an infection was $7^{\circ} \mathrm{C}$ and the temperature range for optimal infection was 15 to $22^{\circ} \mathrm{C}$. Addition of petals to the stem axils increased the rate of lesion formation on the stems but did not alter the temperature requirements. The optimum conditions on OSR were largely in agreement with previous reports on bean $(25,36)$ and lettuce (37). Humidity conditions required for Sclerotinia infections have been described earlier and it was shown that humidity levels may modify temperature requirements $(4,19,37)$. Therefore, SkleroPro uses a function expressing both factors linked in an integral index of infection (INFEST). The limiting conditions are given when INFEST $\geq 0.005$, where the minimum required conditions are 7 to $11^{\circ} \mathrm{C}$ and 80 to $86 \% \mathrm{RH}$ (Fig. 5). Inh significantly correlated with incidence of SSR $\left(R^{2}=0.42\right)$ (Fig. 3). This correlation strongly improved by adding a threshold of continuously suitable conditions required for infection. We tested a range of thresholds from 20 to 30 Inh according to earlier observations (17) and found a threshold of 22 to 23 continuous Inh to provide the best accuracy in the model $\left(R^{2}=0.82\right)$ (Table 2$)$.

A further component critical to the performance of SkleroPro is the simulation of crop development. Because no such model has been published for OSR before, we adapted a GS model from the German Meteorological Service which uses a temperature function and the actual GS to calculate the daily developmental progress $(11,12)$. The resulting GS model, ONTO, achieved a satisfactory accuracy for the critical bud and bloom stages in several field evaluations (Fig. 4). Based on field observations of the date of apothecial development, we decided that GS 58 (late bud) was a suitable starting stage for the model calculation. At GS 68 , calculations were stopped because fungicide sprays were no longer feasible.

Crop-loss relationships for SSR in OSR were lacking; therefore, such data were generated in separate field experiments with artificial inoculations over 3 years $(8,9)$. Due to the single plant inoculations performed in the field to establish variable disease levels, the crop-loss data obtained were undisturbed by fungicide side effects. The resulting crop loss function based on DI at crop maturity was integrated in the forecasting model to determine the economic damage threshold related to spray costs, produce price, and the expected yield. As a result, economic damage thresholds in the model ranged from 13 to $25 \%$ DI, corresponding to yield levels from 5 to 3 tons/ha, respectively. This demonstrates the relatively high tolerance of OSR to SSR and may explain why the damage potential of this disease has been frequently overestimated in the past, resulting in high rates of unnecessary sprays $(8,9,33)$.

Based on the model components described above, a two-tiered forecasting system was finally developed. In the first stage, a regional disease risk assessment is undertaken related to a particular meteorological station and the specific crop rotation. On the second tier, SkleroPro starts a field-site-specific crop loss assessment, determining the threshold DI representing the economic damage threshold and expressed as $\mathrm{Inh}_{\mathrm{i}}$, which is compared with the InhSum. When InhSum reaches $\operatorname{Inh}_{\mathrm{i}}$, the model puts out a recommendation to spray.

The evaluation of SkleroPro with historical data from 1994 to 2004 and in 32 field experiments in 2005 revealed a high accuracy of the model under practical conditions and in diverse geographical situations in Germany. With the historical data collected over 10 years, $70 \%$ of the decisions made by the model were economically correct, whereas $30 \%$ were economically less favorable (24\% overestimated and 6\% underestimated the disease). In the 2005 field trials, $81 \%$ of the decisions made by SkleroPro were economically correct, whereas $19 \%$ of decisions overestimated the disease. In 2005, there was no underestimation of disease, probably because this year was quite unfavorable for stem infection. Two separate studies analyzing field data from 1981 to 2003 reported that 63 and $67 \%$ of sprays against SSR were not economically justified $(8,9,33)$. Therefore, compared with routine sprays which have been common practice in the last decades, SkleroPro would save $39 \%$ of fungicide sprays at bloom as the long-term average, without any loss in productivity of the crop. In extreme years such as 2005 , when a cold spring widely inhibits infection, this saving can go up to $81 \%$, equal to gains in net return of 23 and $45 € /$ ha, respectively. In a separate study with data from the 2005 field experiments, the exact timing of sprays following SkleroPro within the time window from GS 61 to GS 69 provided an additional economic advantage of $18 € /$ ha to the growers compared with the routine timing at full bloom (GS 65) (data not shown).

SkleroPro is the first crop-loss-related forecasting model for a Sclerotinia disease providing to the user a field-site- and timepoint-specific recommendation of fungicide spray in an important field crop. Its practical value results from its high reliability combined with a minimum requirement of field-specific data to be provided by the user. After having been successfully tested in the field in 2005, SkleroPro has been made available to growers and advisors in the 2006 season via an established online infrastructure for agricultural extension through the Internet portal Information System for Integrated Plant Production (ISIP). Therefore, the rationale, components, and implementation of the model could be useful in the development of Sclerotinia disease forecasting systems in other crops and different climates.

\section{ACKNOWLEDGMENTS}

We gratefully acknowledge the significant input of field data by the Federal States plant protection services in Germany. This study was made possible by grants from the German Federal Ministry of Food, Agriculture and Consumer Protection (BMELV) and the Federal German Environmental Foundation (DBU). We thank H. Friesland, German Meteorological Service (DWD), for his valuable advice; and I. Müller and M. Meyer for their excellent technical assistance.

\section{LITERTURE CITED}

1. Abawi, G. S., and Grogan, R. G. 1979. Epidemiology of diseases caused by Sclerotinia species. Phytopathology 69:899-904.

2. Ahlers, D. 1986. Untersuchungen über den Erreger der Weißstengeligkeit Sclerotinia sclerotiorum (Lib.) de Bary an Winterraps-SortenresistenzEpidemiologie_Krankheitsverlauf_Prognose. Dissertation, University of Bonn. 
3. Ahlers, D. 1989. Integrierter Pflanzenschutz bei Pilzkrankheiten an Winterraps. Gesunde Pflanz. 41(9):306-311.

4. Ahlers, D., and Hindorf, H. 1987. Epidemiologische Untersuchungen über den Schaderreger Sclerotinia sclerotiorum an Winterraps im Hinblick auf eine Prognose. Nachrichtenbl. Dtsch. Pflanzenschutzdienst. (Berlin) 39:113-119.

5. Bom, M., and Boland, G. J. 2000. Evaluation of disease forecasting variables for Sclerotinia stem rot (Sclerotinia sclerotiorum) of canola. Can. J. Plant Sci. 80:889-898.

6. Clarkson, J. P., Phelps, K., Whipps, J. M., Young, C. S., Smith, J. A., and Watling, M. 2004. Forecasting Sclerotinia disease on lettuce: Toward developing a prediction model for carpogenic germination of sclerotia. Phytopathology 94:268-279.

7. Cook, G. E., Steadman, J. R., and Boosalis, M. G. 1975. Survival of Whetzelinia sclerotiorum and initial infection of dry edible beans. Phytopathology 65:250-255.

8. Dunker, S. 2006. Untersuchungen zur Schadwirkung von Sclerotinia sclerotiorum (Lib. de Bary) und Verticillium longisporum (comb. nov. Karapapa) in Winterraps (Brassica napus). diss., University of Göttingen, Germany.

9. Dunker, S., and von Tiedemann, A. 2004. Disease yield loss analysis for Sclerotinia stem rot in winter oilseed rape. IOBC 27(19):59-65.

10. Ferraz, L. C. L., Cafe Filho, A. C., Nasser, L. C. B., and Azevedo, J. 1999. Effects of soil moisture, organic matter and grass mulching on the carpogenic germination of sclerotia and infection of bean by Sclerotinia sclerotiorum. Plant Pathol. 48:77-82.

11. Friesland, H. 1998. Ein agrarmeteorologisches Vorhersageverfahren für den Rapskrebs (Sclerotinia sclerotiorum) in Winterraps. Mitt. Biol. Bundesanst. Land-Forstwirtsch. Berlin-Dahlem 357:64.

12. Friesland, H. 2000. Agrarmeteorologisches Verfahren zur Prognose von Rapskrebs. Raps 18(1):14-17.

13. Gentleman, R., and Ihaka, R. 1997. http://www.r-project.org/ Vienna University of Economics and Business Administration, Vienna, Austria.

14. Gracia-Garza, J. A., Neumann, S., Vyn, T. J., and Boland, G. J. 2002. Influence of crop rotation and tillage on production of apothecia by Sclerotinia sclerotiorum. Can. J. Plant Pathol. 24:137-143.

15. Gugel, R. K., and Morall, R. A. A. 1986. Inoculum-disease relationships in Sclerotinia stem rot of rapeseed in Saskatchewan. Can. J. Plant Pathol. 8:89-96.

16. Hao, J. J., Subbarao, K. V., and Duniway, J. M. 2003. Germination of Sclerotinia minor and S. sclerotiorum sclerotia under various soil moisture and temperature combinations. Phytopathology 93:443-450.

17. Jamaux, J., Gelie, B., and Lamarque, C. 1995. Early stages of infection of rapeseed petals and leaves by Sclerotinia sclerotiorum revealed by scanning electron microscopy. Plant Pathol. 44:22-30.

18. Krüger, W. 1975. Die Beeinflussung der Apothezien-und Ascosporenentwicklung des Rapskrebserregers Sclerotinia sclerotiorum (Lib.) de Bary durch Umweltfaktoren. J. Plant Dis. Prot. 82:101-108.

19. Krüger, W. 1975. Über die Wirkung der Witterung auf den Befall des Rapses durch Sclerotinia sclerotiorum (Lib.) de Bary. Nachrichtenbl. Dtsch. Pflanzenschutzdienst. (Berlin) 27:1-6.

20. Lancashire, P. D., Bleiholder, H., Langenlüddecke, P., Stauss, R., Van den Boom, T., Weber, E., and Witzenberger, A. 1991. A uniform decimal code for growth stages of crops and weeds. Ann. Appl. Biol. 119:561-601.

21. Merriman, P. R., Pywell, M., Harrison, G., and Nancarrow, J. 1979. Survival of sclerotia of Sclerotinia sclerotiorum and effects of cultivation practices on disease. Soil Biol. Biochem. 11:567-570.

22. Morall, R. A. A., and Dueck, J. 1982. Epidemiology of Sclerotinia stem rot of rapeseed in Saskatchewan. Can. J. Plant Pathol. 4:161-168.

23. Mueller, D. S., Hartmann, G. C., and Pedersen, W. L. 2002. Effect of crop rotation and tillage system on Sclerotinia stem rot on soybean. Can. J. Plant Pathol. 24:450-456.

24. Nordin, K., Sigvald, R., and Svensson, C. 1992. Forecasting the incidence of Sclerotinia stem rot on spring-sown rapeseed. J. Plant Dis. Prot. 99:245-255.

25. Phillips, A. J. L. 1994. Influence of fluctuating temperatures and interrupted periods of plant surface wetness on infection of bean leaves by ascospores of Sclerotinia sclerotiorum. Ann. Appl. Biol. 124:413-427.

26. Pope, S. J., Varney, P. L., and Sweet, J. B. 1989. Susceptibility of cultivars of oilseed rape to Sclerotinia sclerotiorum and the effect of infection on yield. Asp. Appl. Biol. 23:451-456.

27. Rossi, V., Racca, P., Giosue, S., and Battimani, P. 1997. Decision support systems in crop protection: From analysis of the pathosystem to the computerized model. Petria 7, Suppl. 1:7-26.

28. Singh, U. P., and Singh, R. B. 1983. The effect of soil texture, soil moisture and depth of soil on carpogenic germination of Sclerotinia sclerotiorum. J. Plant Dis. Prot. 90:662-669.

29. Sun, P., and Yang, X. B. 2000. Light, temperature and moisture effects on apothecium production of Sclerotinia sclerotiorum. Plant Dis. 84:12871293.

30. Turkington, T. K., and Morall, R. A. A. 1993. Use of petal infestation to forecast Sclerotinia stem rot of canola: The influence of inoculum variation over the flowering period and canopy density. Phytopathology 83:682-689.

31. Twengström, E., Sigvald, R., Svensson, C., and Yuen, J. 1998. Forecasting Sclerotinia stem rot in spring sown oilseed rape. Crop Prot. 17(5):405411.

32. UFOP. http://www.ufop.de. Berlin, Germany.

33. Wahmhoff, W. 2000. Integrierter Rapsanbau: Untersuchungen zur Entwicklung integrierter Produktionsverfahren am Beispiel des Winterrapses (Brassica napus L.). Erich Schmidt Verlag, Berlin.

34. Wahmhoff, W., Hedke, K., Tiedemann, A. v., Nitzsche, O., and Ulber, B. 1999. Zum Einfluß von Fruchtfolge und Bodenbearbeitung auf die Entwicklung wichtiger Schaderreger des Winterrapses. J. Plant Dis. Prot. 106:57-73

35. Walker, A. 1997. ModelMaker, 4.0 ed. Cherwell Scientific, Oxford.

36. Weiss, A., Kerr, E. D., and Steadman, J. R. 1980. Temperature and moisture influences on development of white mold disease (Sclerotinia sclerotiorum) on great northern beans. Plant Dis. 64:757-759.

37. Young, C. S., Clarkson, J. P., Smith, J. A., Watling, M., Phelps, K., and Whipps, J. M. 2004. Environmental conditions influencing Sclerotinia sclerotiorum infection and disease development in lettuce. Plant Pathol. 53:387-397.

38. Young, C. S., Fawcett, L. E., Anthony, S. G., Smith, J. A., Watling, M., Clarkson, J. P., and Whipps, J. M. 2005. Forecasting Sclerotinia disease in field-grown lettuce. 13th Int. Sclerotinia Workshop, Monterey, CA. 